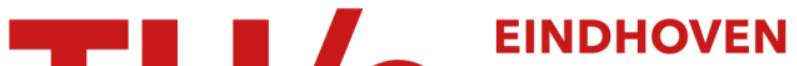 \\ UNIVERSITY OF \\ TECHNOLOGY
}

\section{Dynamical analysis of electrochemical wall shear rate measurements}

Citation for published version (APA):

Steenhoven, van, A. A., \& Beucken, van den, F. J. H. M. (1991). Dynamical analysis of electrochemical wall shear rate measurements. Journal of Fluid Mechanics, 231, 599-614.

https://doi.org/10.1017/S0022112091003531

DOI:

10.1017/S0022112091003531

Document status and date:

Published: 01/01/1991

Document Version:

Publisher's PDF, also known as Version of Record (includes final page, issue and volume numbers)

Please check the document version of this publication:

- A submitted manuscript is the version of the article upon submission and before peer-review. There can be important differences between the submitted version and the official published version of record. People interested in the research are advised to contact the author for the final version of the publication, or visit the $\mathrm{DOI}$ to the publisher's website.

- The final author version and the galley proof are versions of the publication after peer review.

- The final published version features the final layout of the paper including the volume, issue and page numbers.

Link to publication

\section{General rights}

Copyright and moral rights for the publications made accessible in the public portal are retained by the authors and/or other copyright owners and it is a condition of accessing publications that users recognise and abide by the legal requirements associated with these rights.

- Users may download and print one copy of any publication from the public portal for the purpose of private study or research.

- You may not further distribute the material or use it for any profit-making activity or commercial gain

- You may freely distribute the URL identifying the publication in the public portal.

If the publication is distributed under the terms of Article $25 \mathrm{fa}$ of the Dutch Copyright Act, indicated by the "Taverne" license above, please follow below link for the End User Agreement:

www.tue.nl/taverne

Take down policy

If you believe that this document breaches copyright please contact us at:

openaccess@tue.nl

providing details and we will investigate your claim. 


\title{
Dynamical analysis of electrochemical wall shear
} rate measurements

\author{
By A. A. VAN STEENHOVEN \\ AND F. J. H. M. VAN DE BEUCKEN \\ Department of Mechanical Engineering, Eindhoven University of Technology, The Netherlands
}

(Received 11 September 1990)

The performance of a circular electrochemical wall shear rate probe under unsteady flow conditions is analysed through a combined experimental, numerical and analytical approach. The experiments are performed with a ferri- and ferrocyanide redox couple and compared to finite element analyses of the two-dimensional timedependent convection-diffusion equation. The results are related to the analytical Lévêque solution for steady flow and for some cases to Pedley's model for heat transfer in reversing shear flow (Pedley 1976).

The steady flow analyses showed that in our experiments axial diffusion is only of minor importance but that for the lower Péclet numbers $\left(<10^{4}\right)$ three-dimensional effects, like tangential diffusion, may not be neglected. A similar result is found for the oscillating case. A fair agreement is found between experimental and numerical data during flow acceleration, but during flow reversal remarkable (about 15\%) deviations are found. The observed insensitivity of the transducer during flow reversal is quite well predicted by Pedley's model. Finally, the performance of the probe may be improved somewhat by a decrease in cathode length and cathode-anode distance.

\section{Introduction}

The use of an electrochemical technique to measure wall shear rates in fluid flow is based on a diffusion-dependent electrochemical reaction at the surface of an electrode. The net mass flux to the electrode is converted into a measurable electric current, which in turn can be interpreted in terms of wall shear rate. A thorough review of the technique is provided by Mizushina (1971). The main advantages of the electrochemical technique are that the transducer is easy to manufacture, that the wall shear rates can be measured locally (electrode diameter $<1 \mathrm{~mm}$ ), that the fluid flow is not disturbed and that calibration is not necessary. However, the technique is restricted to fluids and only a few electrolyte solutions are usable. Besides, the Lévêque equation for the relation between mass flux and shear rate is often used, which only holds for (quasi-) steady fluid flow.

The electrochemical technique is quite commonly used in fluid dynamics. For example, Choi, Talbot \& Cornet (1979) and Talbot \& Wong (1982) applied it successfully to the measurement of wall shear stress distributions in a circular bend at steady flow conditions. Lutz et al. (1977) and Hong, Shu \& Hwang (1985) used the technique to investigate the steady flow situations in models of human arteries. Most often in the experiments a circular probe is used and a large number of theoretical efforts are made to describe adequately the behaviour of the electrochemical or the similar hot-film probes in steady flow. The leading term of the steady boundary 
solution was derived by Lévêque (1928), leading to the widely used one-third power law between the local wall shear rate and the values of the Sherwood or Nusselt number. The importance of the neglected axial diffusion term in steady flow conditions was first analysed by Ling (1963). Also, numerical solutions of the steady convection-diffusion equation have been carried out for strip-shaped films by Cognet (1971) and for disk-shaped films by Py \& Gosse (1969). Recently, Phillips (1990) extended this work by an analytical study of heat transfer at various Péclet numbers from isothermal circular disk-shaped films. Stone (1989) used his estimates for the neglected flux from the edge regions to develop a correction to the asymptotic expressions.

Also the dynamical behaviour of the transducer in situations with a smallamplitude sinusoidal modulation of steady flow attracted a lot of scientific interest. Fortuna \& Hanratty (1971) and Mao \& Hanratty (1985) determined theoretically the transfer function of the response of the probe to the imposed oscillations, while Mitchell \& Hanratty (1963) used the method for the analysis of turbulence close to the wall. More recently, Talbot \& Steinert (1987) measured the frequency response for a laminar, sinusoidally oscillating flow superimposed on a steady flow in a straight tube, while Deslouis et al. (1990) tested the theoretical predictions very carefully by using a rotating disk.

The dynamical behaviour of the transducer in flow situations where low-frequency high-amplitude fluctuations in the wall shear rate are present is much less investigated. Experimental information is gained by Seed \& Wood (1970) and Clark (1974), who performed unsteady calibration experiments with a hot-film anemometer in flow situations with temporary shear reversal at the probe wall. Pedley (1976) derived an asymptotic expansion solution for the heat transfer of a hot film in pulsatile flow and combined this with a purely diffusive solution during shear reversal. Comparison of Pedley's model with the results of Clark revealed that the shape of the predicted curve of heat transfer against time agrees very well with the experimental one, but its phase shows a lead of approximately $\frac{1}{4} \pi$ over the experimental curve. It was concluded by Pedley that the most probable cause of the unwanted phase lead lies in the three-dimensional nature of the velocity and temperature fields over the hot film, because the probe is not mounted on a flat plate but on a cylinder, and because diffusion in the cross-stream direction tends to increase the 'thermal inertia' of the probe. The same flow situation is investigated by Kaiping (1983), who examined numerically the unsteady forced convective heat transfer from a hot film in among others, reversing shear flow. He concluded that in reversing flow a considerable influence of the thermal wake can be seen and that about half of the phase lag between Pedley's solution and Clark's experiments has to be attributed to the strong simplifications in Pedley's model. Finally, Mao \& Hanratty (1991) extended the numerical work of Kaiping and tried to solve the inverse problem of calculating the variation of wall shear rate from given mass transfer rate with time.

The aim of the present study is to analyse the dynamical response of the electrochemical wall shear rate transducer through a combined experimental, numerical and analytical approach and to evaluate this technique for use in flow situations with severe backflow (like, for example, in models of arterial bifurcations). The experiments are performed with a ferri-and ferrocyanide redox couple in a straight tube with fully developed unsteady flow. To prevent flow distortions the electrochemical transducer is flush-mounted in the wall. In order to describe the relation between fluid flow and mass transport for this particular case, the unsteady 


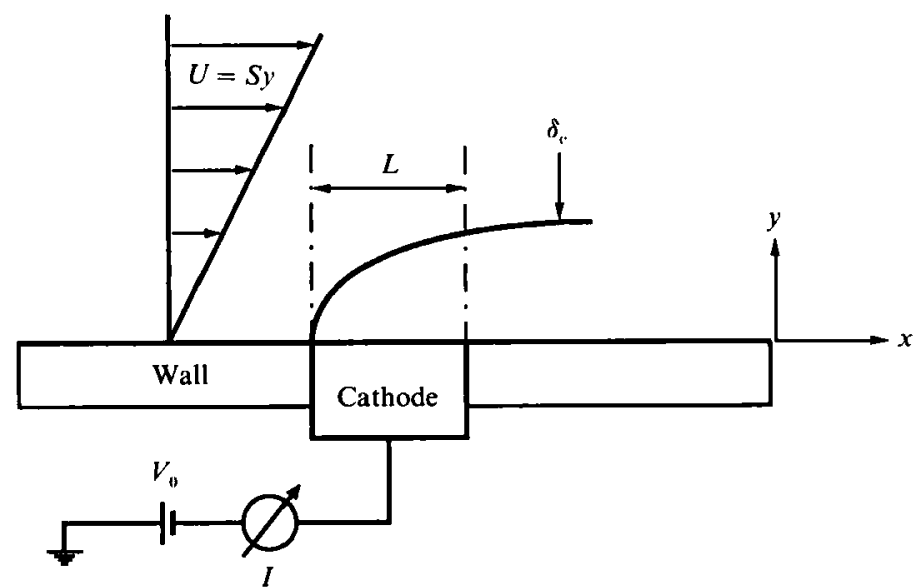

FIGURE 1. Diagram of the electrochemical wall shear rate transducer.

convection-diffusion equation is solved numerically for flow waveforms with and without severe backflow. As a test of the experimental set-up and the numerical model, the static response of the transducer is first determined. Next, unsteady flows with a variable mean component are investigated and the results are compared with the analytical quasi-steady Lévêque solution and in some cases with Pedley's model. Finally, a concise parameter variation study was performed to improve the transducer for measurements during flow reversal.

\section{Basic equations}

In figure 1 a schematical drawing is given of the problem to be solved. A mixture of ferricyanide and ferrocyanide in sodium hydroxide is used as the fluid. The chemical reaction at the electrodes is described as:

$$
\mathrm{Fe}(\mathrm{CN})_{6}^{3-}+\mathrm{e}^{-} \underset{\text { Anode }}{\stackrel{\text { Cathode }}{\rightleftharpoons}} \mathrm{Fe}(\mathrm{CN})_{6}^{4-} .
$$

The conversions of ferricyanide and ferrocyanide that take place between the cathode and the anode maintain a constant concentration of both chemicals. The ion flux can be determined by measuring the electric current flowing between the electrodes (Hanratty \& Campbell 1983). According to Faraday,

$$
\frac{1}{A} \int_{A} N \mathrm{~d} A=\frac{I}{A F},
$$

where $N$ is the local ion flux per unit area, $I$ is the measured current, $A$ is the surface area of the cathode and $F$ is the Faraday's constant. Commonly the ion flux is expressed by the Sherwood number, defined as

$$
S h=\frac{L}{C_{0} D} \frac{I}{A F} .
$$

Here $C_{0}$ is the bulk concentration of ferricyanide ions, $D$ its diffusion coefficient and $L$ the length of the probe. In our case a circular probe is used, but for comparison of the experiment with the two-dimensional theoretical models it will be treated as a rectangle with an effective length in the flow direction (Hanratty \& Campbell 1983),

$$
L_{\mathrm{e}}=0.8139 d \text {, }
$$


with $d$ the diameter of the electrode. The major drawback of defining such an effective length is that in its derivation the influence of tangential diffusion (in the direction perpendicular to the flow) is neglected. As stated earlier by Reiss \& Hanratty (1963) the validity of such an assumption for a circular electrode is uncertain, since the fluid flowing over the centreline of the electrode will have a longer contact time than fluid flowing over the electrode near its edges. However, numerical analysis of, among others, Py \& Gosse (1969) demonstrated that (4) may be used provided that the mass related Péclet number $(Z)$ is larger than $10^{3}$. For smaller $Z$-values corrections terms have been derived by Phillips (1990) and Stone (1989).

The diffusion of the ferricyanide to the cathode is governed by the shear-ratedependent boundary layer $\delta_{c}$ at the surface of the cathode. This mass transport problem is described by the convection-diffusion equation for the reacting ions (ferricyanide) in the fluid mixture. For the two-dimensional fully developed laminar boundary flow, as defined in figure 1 , this equation reads

$$
\frac{\partial C}{\partial t}+S(t) y \frac{\partial C}{\partial x}=D\left[\frac{\partial^{2} C}{\partial x^{2}}+\frac{\partial^{2} C}{\partial y^{2}}\right],
$$

with $C$ the molar concentration of the ferricyanide ions in the mixture and $S(t)$ the time-dependent velocity gradient at the wall. The linearization of the velocity profile $(u=S y)$ within the concentration boundary layer is justified as the Schmidt number $S c \approx 2400$ is large.

Introducing the dimensionless variables [of $O(1)$ ],

$$
\left.\begin{array}{c}
x^{\prime}=\frac{x}{L}, \quad y^{\prime}=y\left[\frac{S_{\mathrm{ref}}}{L D}\right]^{\frac{1}{3}}, \quad t^{\prime}=t \omega, \quad C^{\prime}=\frac{C}{C_{0}}, \\
S^{\prime}\left(t^{\prime}\right)=\frac{S(t)}{S_{\text {ref }}}, \quad Z=\frac{S_{\text {ref }} L^{2}}{D}, \quad S r=\frac{\omega L^{\frac{2}{3}}}{S_{\text {ref }}^{\frac{2}{3}} D^{\frac{1}{3}}}
\end{array}\right\}
$$

and omitting the accents yields

$$
S r \frac{\partial C}{\partial t}+S(t) y \frac{\partial C}{\partial x}=Z^{-\frac{2}{3}} \frac{\partial^{2} C}{\partial x^{2}}+\frac{\partial^{2} C}{\partial y^{2}} .
$$

Here $S_{\text {ref }}$ is a characteristic or the mean value of the velocity gradient, $\omega$ is the angular frequency, $Z$ is the Péclet number for mass transfer and $S r$ is the Strouhal number. The velocity gradient reads in dimensionless form:

$$
S(t)=1+\beta \sin t \text {. }
$$

This implies that when $\beta>1$, backflow is involved. For quasi-steady flow conditions $(S r \ll 1)$ and large $Z$-values the solution of $(7)$ reduces to the so-called Lévêque solution (1928):

and

$$
\begin{gathered}
S h_{x}(t)=-\left(\frac{\partial C}{\partial y}\right)_{y=0}=0.538\left[\frac{S(t) L^{2}}{D}\right]^{\frac{1}{3}}\left[\frac{1}{x}\right]^{\frac{1}{3}}, \\
S h(t)=\int_{0}^{1} S h_{x} \mathrm{~d} x=0.808\left[\frac{S(t) L^{2}}{D}\right]^{\frac{1}{3}} .
\end{gathered}
$$

According to Ling (1963) axial diffusion (in the direction of the flow) can be neglected for $Z>500$. To find whether the concise relation (10) between measured mass flux $[S h(t)]$ and velocity gradient $[S(t)]$ can also be used under unsteady flow conditions, this solution will be compared with the numerical solution of the unsteady convection-diffusion equation. 
Finally, some of the numerical solutions will also be compared with the results of the analytical model derived by Pedley (1976). He described the dynamical behaviour of a hot-film anemometer under unsteady flow conditions with a temporary backflow at the wall. He also assumed a two-dimensional boundary layer, in which $S(t)$ is positive for $t<0$ and changes its sign at $t=0$. The axial diffusion terms were neglected. Pedley assumed that long before reversal $\left(t<-t_{1}\right)$ the flow at a point on the plate will be quasi-steady and that long after reversal $\left(t>t_{2}\right)$ the flow will be quasi-steady again, but with the leading edge at the other end of the plate. In between $\left(-t_{1}<t<t_{2}\right)$ the flow is governed approximately by the diffusion equation, but $t_{1}$ and $t_{2}$ are not $a$ prior $i$ known. He chose $t_{1}$ such that the displacement thickness of the boundary layer remains constant at $t=-t_{1}$. Similarly $t_{2}$ was determined. Another critical assumption in this model is that the transition between a quasi-steady and a purely diffusive solution is not gradual but abrupt. The validity of this model will be investigated by comparing Pedley's results with the corresponding solutions of the complete set of equations. To that end it has to be mentioned that Pedley described the form of shear variation in dimensionless form by

$$
S(t)=1+\alpha_{1} \cos \omega_{1}, t
$$

which is related to our situation by $\alpha_{1}=\beta$ and $\omega_{1}=S r$. Pedley's predicted values were taken directly from his figure 3 and shifted with $\frac{1}{2} \pi$ before comparing with our results.

\section{Numerical model}

Equation (7) has been solved with the use of a standard finite-element method (Cuvelier, Segal \& van Steenhoven 1986). The mathematical domain and the boundary conditions are shown in figure $2(a)$. As an approximation for $C(x, y, t)$ a linear combination of time-independent basis functions $\phi_{i}$ is taken:

$$
C(x, y, t)=\sum_{i=1}^{N} C_{i}(t) \phi_{i}(x, y)
$$

The basis functions are constructed such that

$$
\phi_{i}\left(x_{j}\right)=\phi_{i j} \text { with } \quad x_{j}=\left(x_{j}, y_{j}\right)
$$

at every chosen nodal point $x_{j}$. The quantities $C_{t}(t)$ then denote the approximation of the concentration in nodal point $x_{i}$. The domain $\Omega$ is divided into triangular elements, see figure $2(b)$, with three nodal points. The corresponding basis functions are linear functions of the space coordinates. Theoretically, the spatial accuracy of approximation is $O\left(h^{2}\right)$, where $h$ is the maximal diameter of the element.

Using Galerkin's method, (7) is transformed into the following set of linear equations

$$
\operatorname{Sr} \boldsymbol{M} \dot{C}+\boldsymbol{S}(Z) C=0
$$

where $C$ is the vector of unknown concentration values, $\dot{C}$ is its time derivative, while the matrices $M$ and $\boldsymbol{S}$ are defined as:

$$
\begin{gathered}
M_{i j}=\int_{\Omega} \phi_{i} \phi_{j} \mathrm{~d} x \mathrm{~d} y \quad(i=1, \ldots, N, \quad j=1, \ldots, N) \\
S_{i j}=\int_{\Omega}\left[Z^{-\frac{2}{8}} \frac{\partial \phi_{i}}{\partial x} \frac{\partial \phi_{j}}{\partial x}+\frac{\partial \phi_{i}}{\partial y} \frac{\partial \phi_{j}}{\partial y}+S y \phi_{i} \frac{\partial \phi_{j}}{\partial x}\right] \mathrm{d} x \mathrm{~d} y \quad(i=1, \ldots, N, \quad j=1, \ldots, N) .
\end{gathered}
$$


(a)

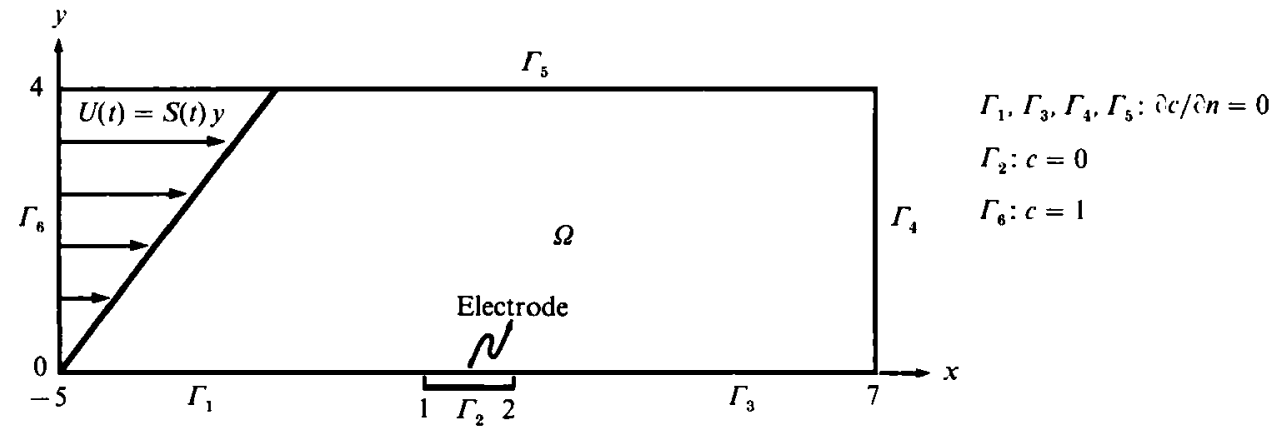

(b)

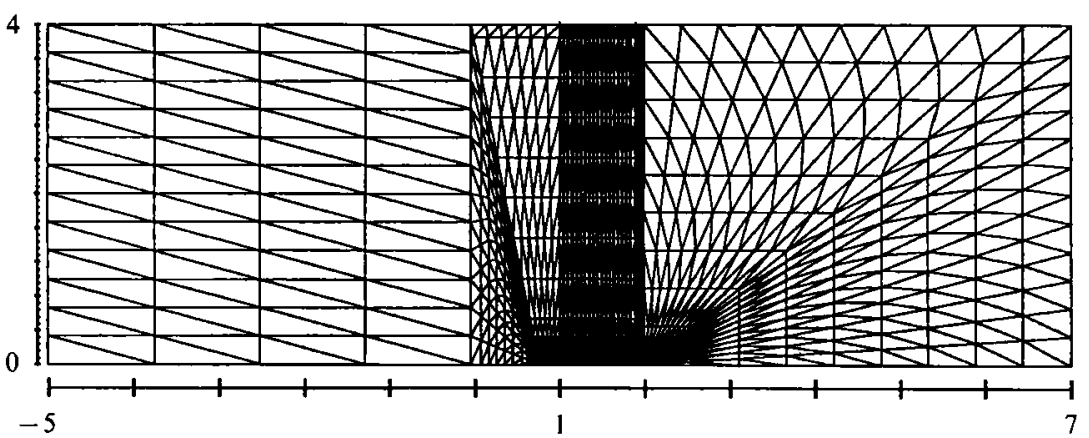

(c)

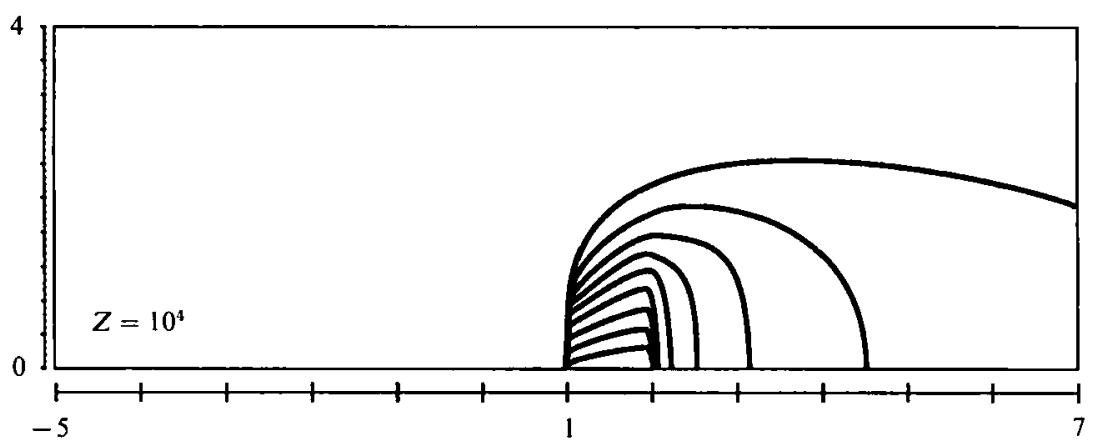

FiguRe 2. (a) Boundary conditions, (b) element distribution and (c) a typical numerical result (isoconcentration lines) at steady flow.

The construction of the system of equations is carried out with the finite element package SEPRAN (Segal 1984).

The time derivative in the discrete equation (14) is approximated by a finite difference $\theta$-method (Van de Vosse et al. 1986). The equation then becomes:

$$
\operatorname{Sr} M \frac{C^{n+1}-C^{n}}{\Delta t}+S^{n+\theta} C^{n+\theta}=\mathbf{0},
$$

with

$$
\begin{aligned}
& C^{n+\theta}=\theta C^{n+1}+(1-\theta) C^{n} \\
& \boldsymbol{S}^{n+\theta}=\theta \boldsymbol{S}^{n+1}+(1-\theta) \boldsymbol{S}^{n}
\end{aligned}
$$

and

$$
\begin{gathered}
C^{n}=C(n \Delta t), \\
0 \leqslant \theta \leqslant 1 .
\end{gathered}
$$



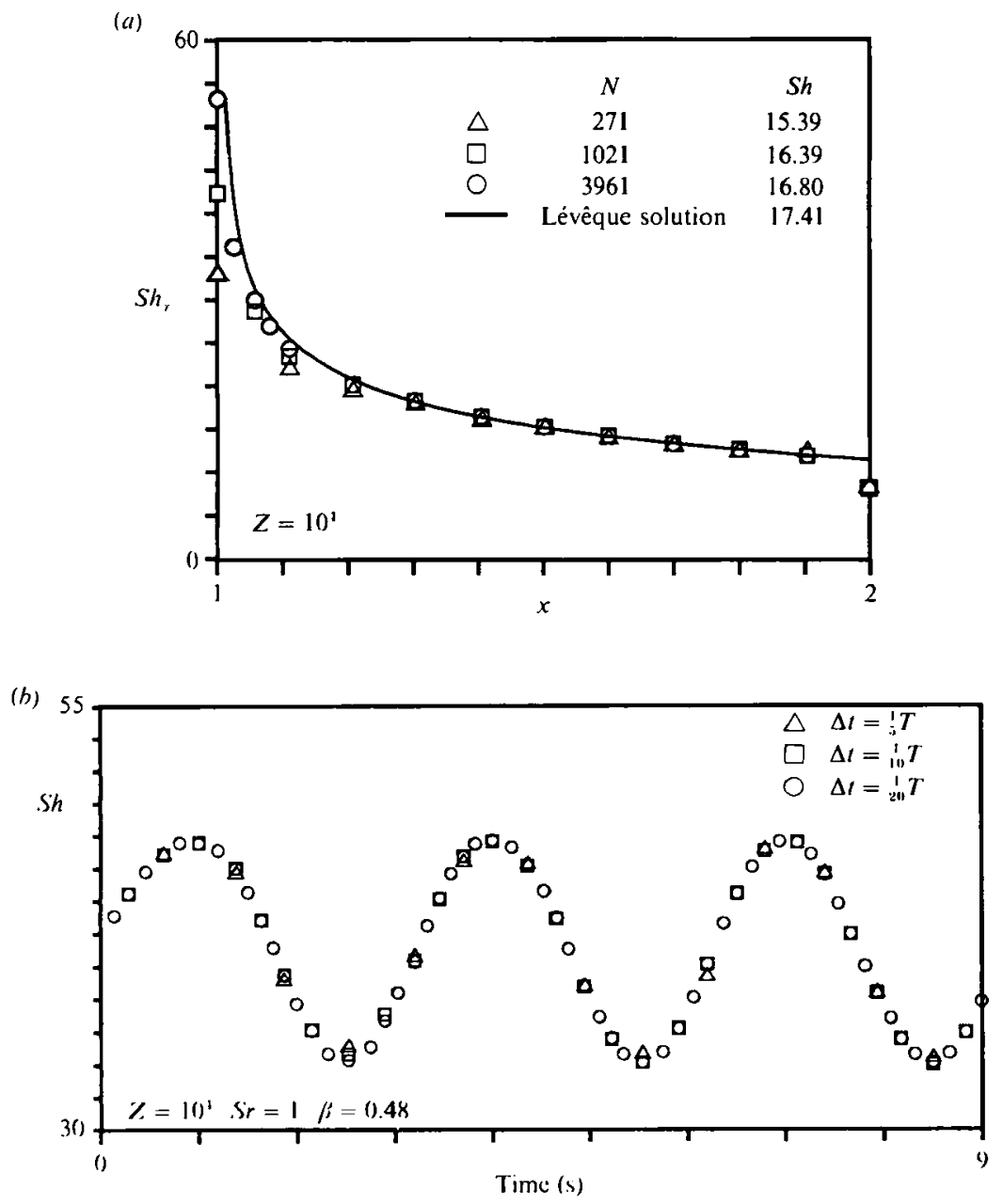

Figure 3. The influence of $(a)$ the number of nodal points $(N)$ at steady flow and $(b)$ the number of timesteps per flow period $(T)$ at unsteady flow on the local $\left(S h_{x}\right)$ and total Sherwood $(S h)$ numbers.

For $\theta=0$ (Euler-explicit) and $\theta=1$ (Euler-implicit) the global error of the scheme is $O(\Delta t)$, while for $\theta=0.5$ (Crank-Nicolson) a second-order accuracy $\left[O\left(\Delta t^{2}\right)\right]$ is expected. For $0 \leqslant \theta \leqslant 0.5$ the scheme is only conditionally stable. As the initial condition the steady-state solution for $S=1$, see (8), is used. To damp disturbances induced by the transition from the initial state, in the first period of the flow oscillation the equations are integrated with the Euler-implicit scheme after which the Crank-Nicolson scheme is used. The calculations are stopped when the differences in the solution at the last timestep of two succeeding flow cycles are smaller than a prescribed value. Normally three periods appear to be sufficient.

To find the optimum values or conditions for mesh distribution, boundary condition at $\Gamma_{5}$, degree of interpolation polynomial, number of elements and number of timesteps, some numerical test calculations were first carried out. Some typical examples for $Z=10^{4}$ are shown in figure 3 , where the number of elements and timesteps are varied. In figure $3(a)$ the numerical solution of the steady convection-diffusion equation without the axial diffusion term is solved and 
compared to the Lévêque solution using (9). As expected, the major differences occur near the edges where a singularity in boundary conditions is present. Owing to the local mesh refinements at the leading edge, which makes an $O(1)$ contribution to the total Sherwood number, the numerical error in case of the finest mesh distribution is quite small $(\approx 3 \%$ ). Hence, for the actual calculations in the steady case 7680 elements with 3961 nodal points were used. To reduce the amount of calculation time, in the unsteady case 1920 elements with 1021 nodal points and 20 timesteps during a flow cycle were applied. The calculations were performed on a PRIME minicomputer on which for the unsteady case about 2 hours CPU-time was needed.

\section{Experimental methods}

Figure 4 shows a diagram of the fluid circuit. A gear pump (Verder 2032) was used to create the steady-flow component while the unsteady-flow component was generated by a plunger pump. To ensure a pure sinusoidal flow modulation, the ratio of plunger displacement to driveshaft length was chosen to be less than 0.01. Before entering the measurement section, the fluid passed through a long circular tube both having an internal diameter of $9.8 \mathrm{~mm}$. The length of the tube (125 diameters) was chosen such that even at the highest Reynolds number $(\approx 1500)$ the fluid flow was fully developed there (Schlichting 1979). To eliminate the influence of ambient temperature variations the circulating fluid was kept at a constant temperature of $26{ }^{\circ} \mathrm{C}$ using a thermostat. As test fluid, demineralized water was used in which $0.01 \mathrm{M}$ potassium ferricyanide, $0.01 \mathrm{~m}$ potassium ferrocyanide and $1 \mathrm{~m}$ sodium hydroxide was dissolved. The density of the solution was calculated to be $1.056 \times 10^{3} \mathrm{~kg} \mathrm{~m}^{-3}$. For the dynamic viscosity and diffusivity of the ferricyanide solution empirical temperature-dependent relationships of Bazan \& Arvia (1965) were used yielding the values of $\eta=1.08610^{-3} \mathrm{~kg} \mathrm{~s}^{-1} \mathrm{~m}^{-1}$ and $D=6.6810^{-10} \mathrm{~m}^{2} \mathrm{~s}^{-1}$, respectively. The system was purged with nitrogen gas to reduce the oxidation of the test fluid.

The cathode of the transducer was a circular nickel electrode (diameter $1 \mathrm{~mm}$ ) flush-mounted in the wall of the measurement section. The anodes were also made of nickel and were placed $60 \mathrm{~mm}$ upstream and downstream of the cathode. The larger surface area of the anode relative to the cathode $(150: 1)$ assured that the current to be measured was limited by the reaction at the cathode. Between the cathode and anode a constant voltage difference $(0.5 \mathrm{~V})$ was applied. It was verified that the cathode current, measured by the voltage difference over a reference resistor, had reached its limiting value so that the process was indeed diffusion limited. The volume flow was measured electromagnetically (Skalar Transflow 601). The mass flux and flow rate signals were fed into a mini-computer (PRIME 750) using a sample rate of $100 \mathrm{~Hz}$. To increase the measuring accuracy the results were averaged over 10 samples, or in the unsteady case over 10 flow cycles. A typical result is given in figure 5. Owing to the relatively large amplitude of the unsteady flow component the response of the wall shear rate transducer during flow acceleration and deceleration differs significantly. Next, the measured flow rate signal was used to calculate the wall shear rates, assuming fully developed pipe flow (Uchida 1956), and to calculate the Sherwood numbers on the basis of the Lévêque solution using (10). Finally, the experimentally (equation (3)) and numerically (left-hand part of (10)) determined Sherwood numbers were plotted with the Lévêque reference solution as a function of time for each set of flow conditions.

The experiments were performed under steady and unsteady flow conditions. In the steady case the Reynolds number, defined as $R e=U D / \nu$ with $U$ the mean 


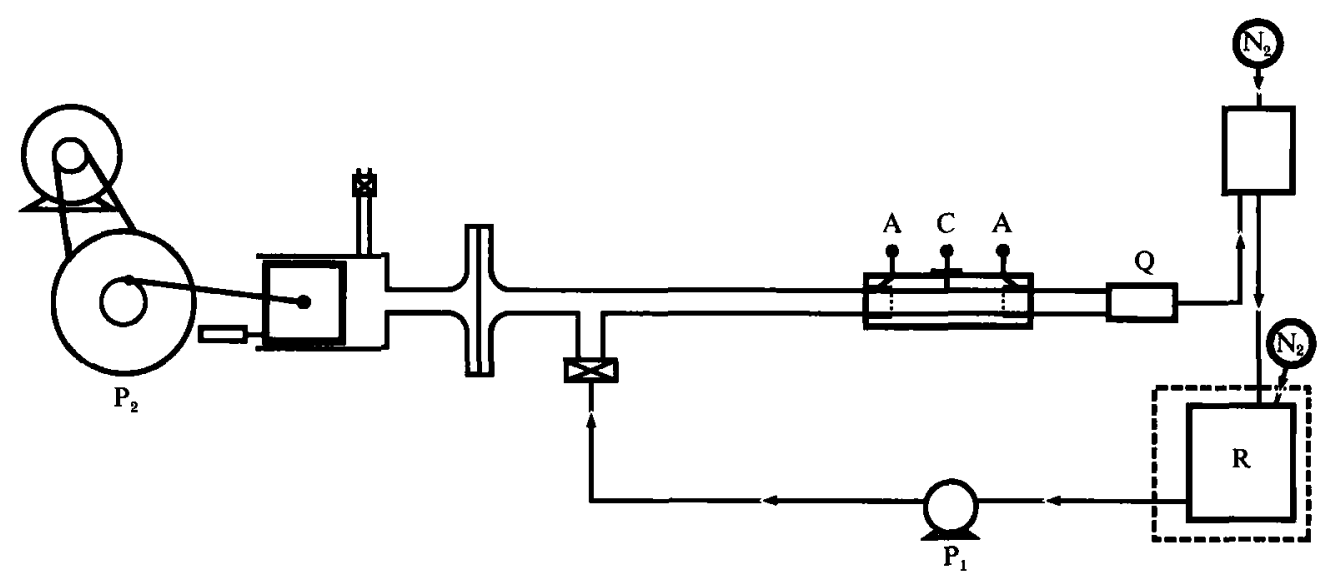

Figure 4. Diagram of the experimental set-up. $C=$ Cathode, $A=$ Anode, $Q=$ Flow meter, $R=$ Reservoir, $\mathrm{P}_{1}=$ Gear pump, $\mathrm{P}_{2}=$ Plunger pump.

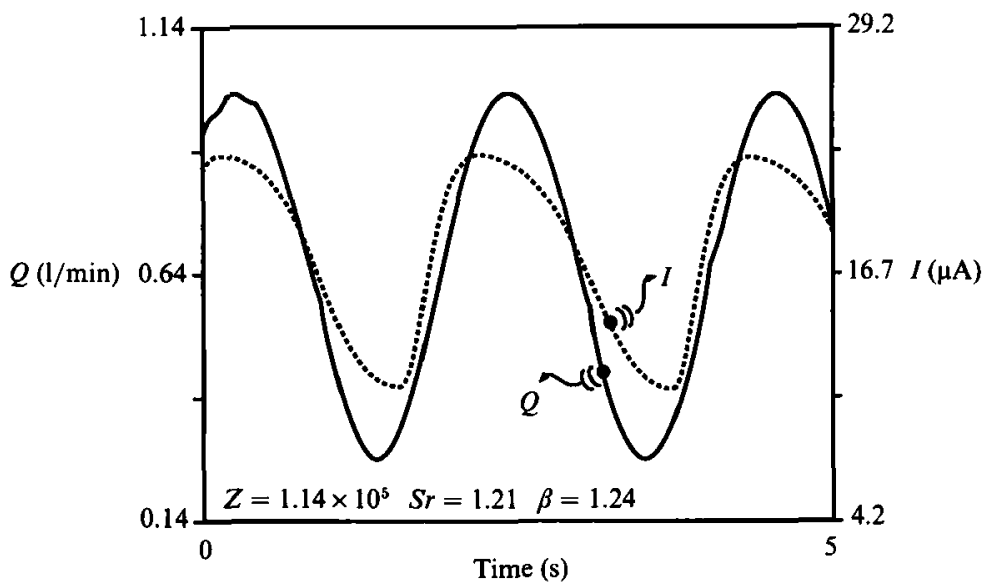

Figure 5. Typical response of the transducer $(I)$ at a pulsating flow rate $(Q)$.

velocity in, and $D$ the diameter of, the measurement section and $\nu$ the kinematic viscosity, was varied between 20 and 1500 . According to (6) and under the assumption of Poiseuille flow the corresponding $Z$-value varies between about $2 \times 10^{3}$ and $2 \times 10^{5}$. For the unsteady case the Strouhal number, also defined by $(6)$, was varied between 0.66 and 1.35 , while the amplitude parameter (see (8)), was varied between 0.48 and 1.72. Owing to the limitations in the experimental set-up the amplitude ratio and the Strouhal number were not varied independently of each other. As a consequence the $Z$-value then varies slightly, although in all situations the magnitude order was $10^{5}$.

\section{Results}

To test the numerical and experimental method, first some steady flow analyses were performed. In figure $6(a)$ the numerical data for the cases with and without axial diffusion are compared to the Lévêque solution for $Z$ values between 100 and $2 \times 10^{5}$. Even for small $Z$-values the influence of axial diffusion is small. As expected, the maximal difference occurs at the lowest $Z$-value and amounts to about $5 \%$. For 

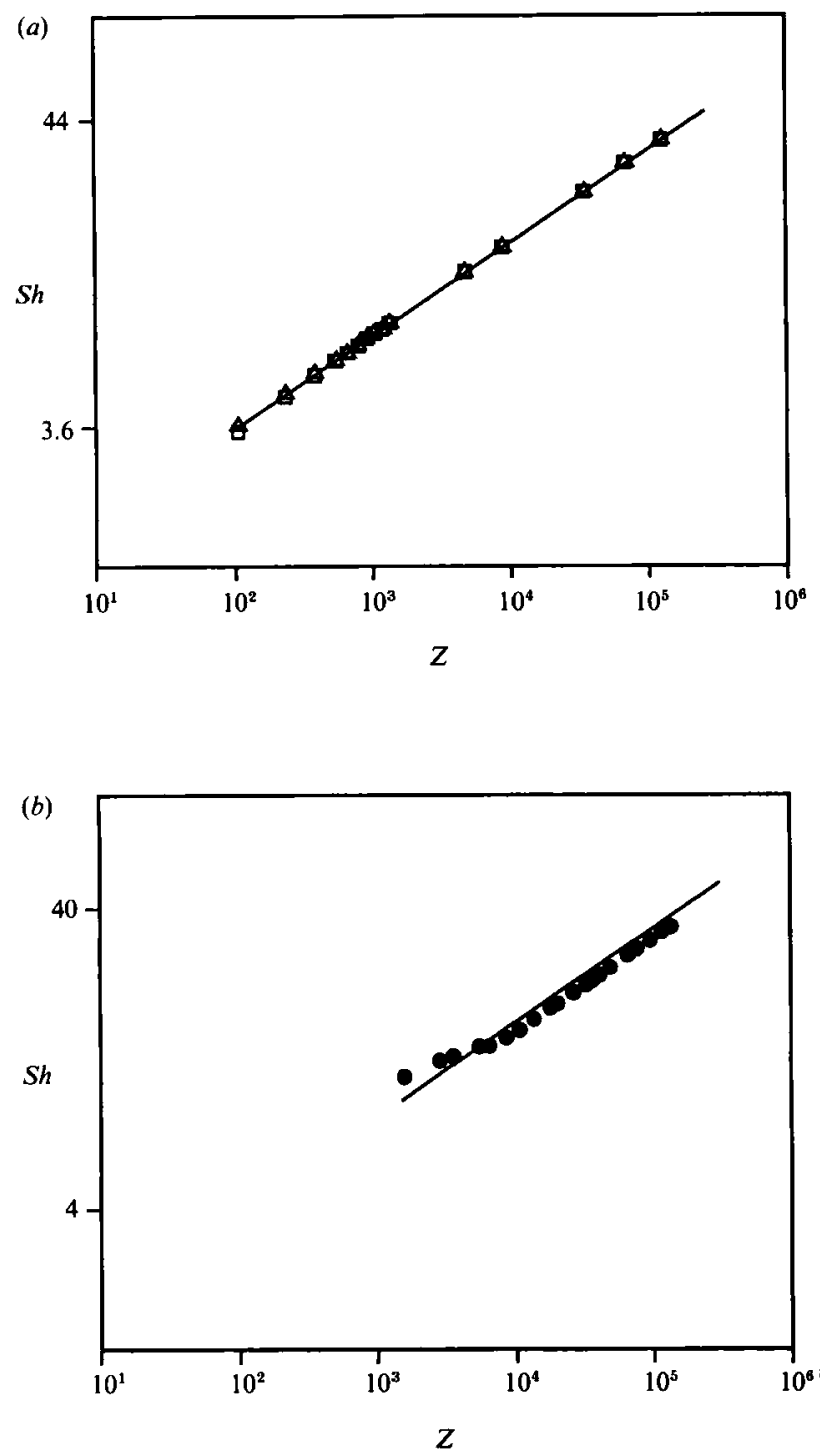

Figure 6. Comparison of the $(a)$ numerical and $(b)$ experimental responses of the transducer with the Lévêque solution at steady flow. Symbols: $\square$, numerical without axial diffusion; $\triangle$, numerical with axial diffusion;, experiments; - Lévêque solution. The Sherwood and $Z$-number values are both plotted on a logarithmic scale.

the whole range the differences between the numerical and analytical results appear to be smaller than $5 \%$. The experimental results are compared with the Lévêque solution in figure $6(b)$. For $Z>10^{4}$ the measured mass flux values are about $8 \%$ smaller than the Lévêque solution, probably owing to the uncertainty in the value of the diffusivity. The discrepancies between theory and experiment for $Z<10^{4}$ are probably due to the tangential diffusion as suggested by Hanratty \& Campbell (1983) and estimated among others by Phillips (1990) and Stone (1989). However, it has to be stated that the consistently observed deviation at $Z=10^{3}$ (about $20 \%$ ) is much larger than predicted by Phillips by his equation (33) (about 3\%) and that other sources like measurement inaccuracies at low $Z$-values may not be neglected. 


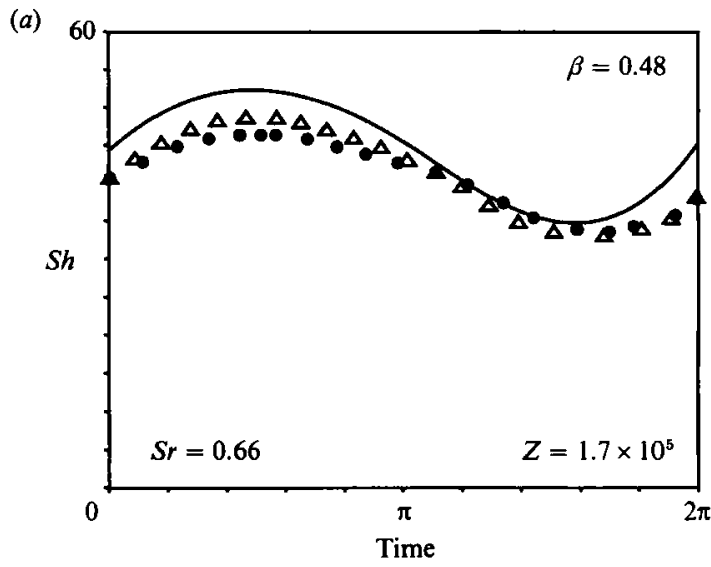

(b)

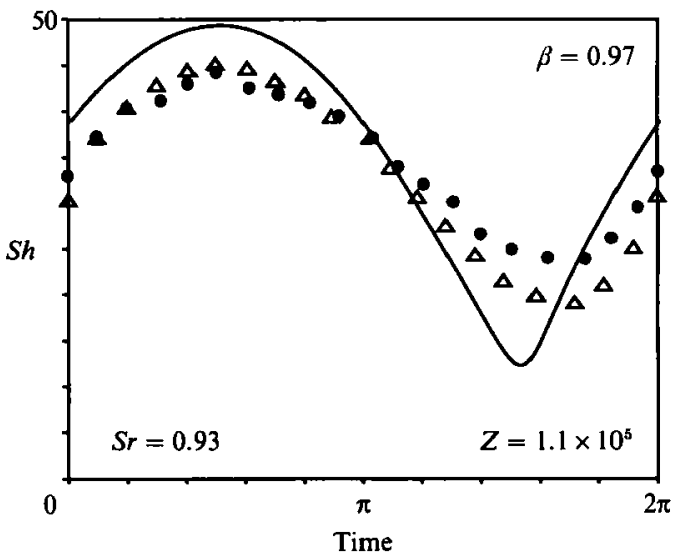

Figure 7. $\triangle$, Numerical, and 0 , experimental responses of the transducer at unsteady flow in cases without flow reversal. (a) $\beta=0.48, S r=0.66 ;(b) \beta=0.97, S r=0.93$. As a reference also , the Lévêque solution is given.

Next, time-dependent fluid flow was investigated. In figure 7 the experimental, numerical and analytical Sherwood values as a function of time are shown for an oscillatory flow rate without backflow $(\beta<1)$. As expected, the differences between the values for the unsteady measurement and calculations with the steady Lévêque solution are the highest (maximal $45 \%$ ) at the higher $\beta$ and $S r$-numbers (figure $7 b$ ). For the lower values of these parameters (see figure $7 a$ ) a maximal difference of about $11 \%$ is found. In the high-amplitude flow case a relatively large difference (about $16 \%$ ) is observed at minimal mass flux between the experimental and numerical data, which is probably primarily a consequence of the tangential diffusion discussed earlier. Also, the relatively coarse element distribution and a not-completelysinusoidal plunger motion in the experiments may be attributed to this. In figure 8 the results are given for an oscillating flow rate, where during a part of the flow cycle severe backflow occurs. The behaviour then differs completely from the Lévêque solution. For the low shear rate values the mass flux is higher than expected for the steady case, while in the maxima of the curves the differences are much smaller. The insensitivity of the transducer during flow reversal is probably partly caused by the 
(a)

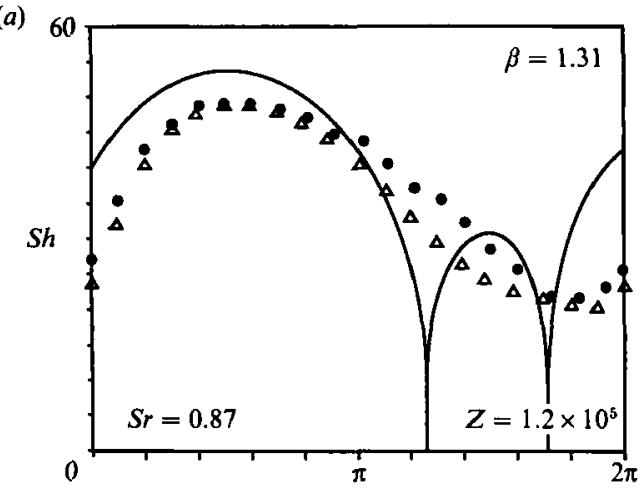

(b)

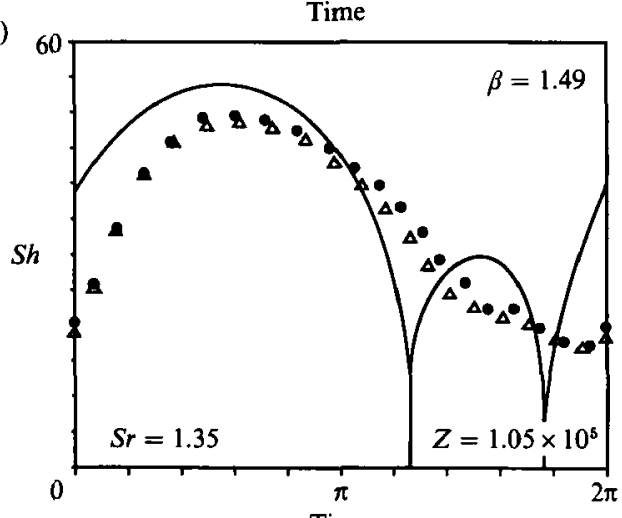

(c)

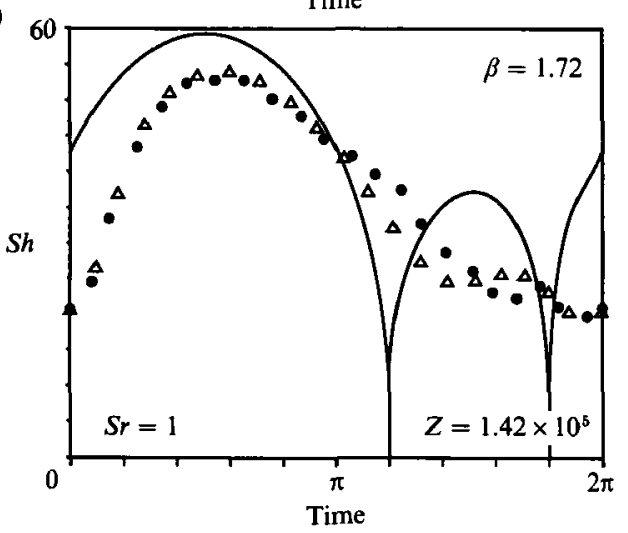

Figure 8. $\triangle$, Numerical, and $\bigcirc$, experimental responses of the transducer at unsteady flow in cases with flow reversal $(a) \beta=1.31, S r=0.87 ;(b) \beta=1.49, S r=1.35 ;(c) \beta=1.72, S r=1$. As a reference also —-, the Lévêque solution is given.

dominant influence of diffusion over convection during that phase at low $\beta-1$ values and partly by the fact that fluid with a relatively low potassium ferricyanide concentration (from the so-called concentration wake) is carried back over the cathode during shear reversal. The agreement between experimental and numerical data is fair, especially during flow acceleration, and also the mass flux plateau during flow reversal is predicted adequately. The largest deviations (about 20\%) occur during flow reversal and are again expected to be due to tangential diffusion. This is supported by the fact that an increase in Strouhal number leads to a considerable 
(a)

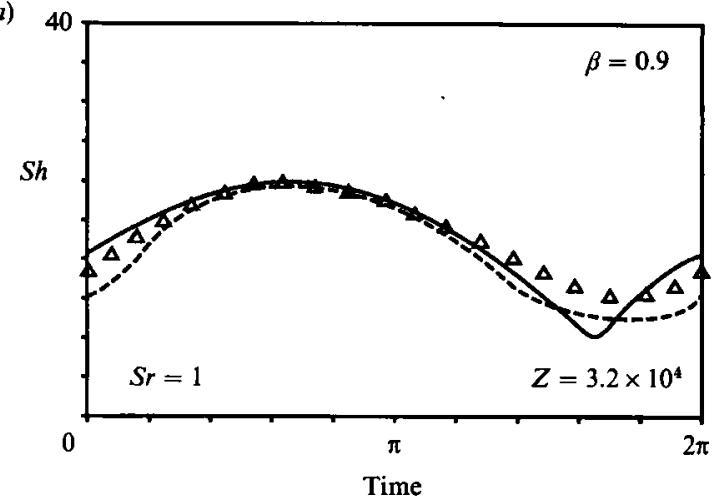

(b)

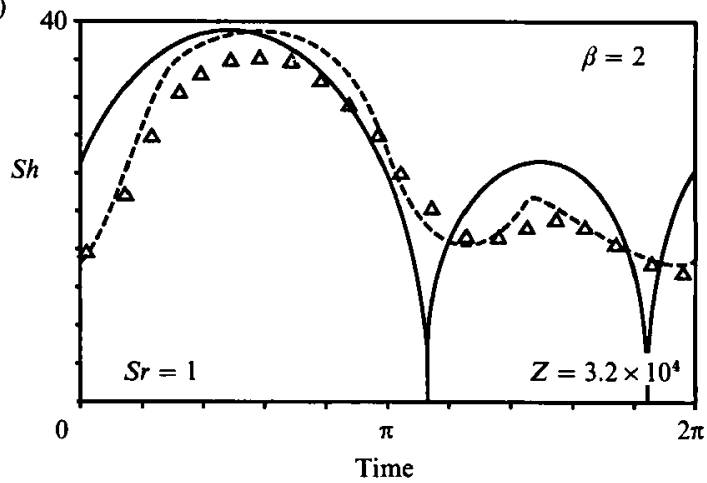

Figure 9. Comparison of $\triangle$, numerical data with --- , those of Pedley (1976) (a) $\beta=0.9$, $S r=1 ;(b) \beta=2, S r=1$. As a reference also - , the Lévêque solution is given.

reduction of the observed deviation (compare figures $8 b$ and $8 a$ ). Numerical results are also compared with Pedley's (1976) data. The Sherwood values found are shown in figure 9 for $S r=1$ and the cases without and with backflow. As also found by Kaiping (1983), during flow reversal a phase lag of about $\frac{1}{8} \pi$ is observed between Pedley's predictions and our numerical results. Besides, the mass flux at maximal shear rate as predicted by Pedley's model is, for the high-amplitude case, somewhat higher than the one obtained from the numerical model. Anyhow, despite the severe simplifications made, the analytical model appears to predict the actual behaviour quite well.

Finally, to improve the transducer design the numerical model was used to perform a concise parameter variation study. As during flow reversal the transducer is almost insensitive to shear variations, attention was focused on the flow situation with $\beta=1.72$. The Lévêque solution was taken as reference. First, the Strouhal number was varied. The results are shown in figure $10(a)$. As expected, the lower the Strouhal number, the better the numerical mass flux values follow the steady Lévêque solution. This also implies (see (6)) that the performance of the transducer improves by lowering the cathode length or by using a fluid with a higher diffusivity. A third improvement is expected when the ion concentration in the fluid which reverses above the cathode exhibits normal values. This may be realized by shortening the cathode-anode distances and figure $10(b)$ shows some results. Indeed, some, but not spectacular, changes in the numerically predicted mass flux curves are observed. 
(a)

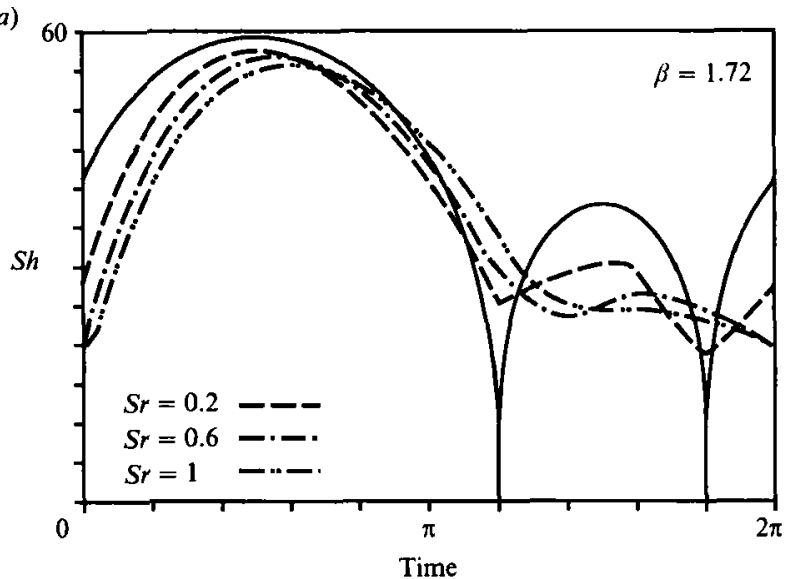

(b)

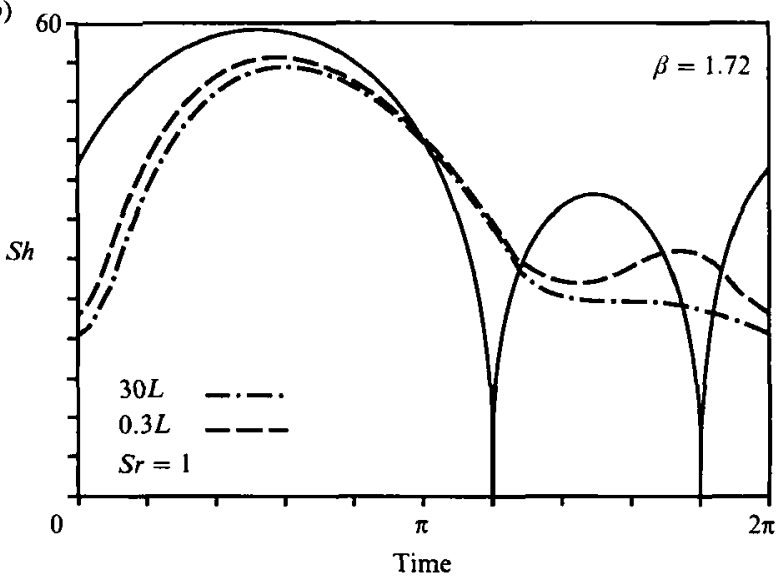

Figure 10. The influence of $(a)$ the Strouhal number and $(b)$ the anode-cathode distance on the response of the transducer at unsteady flow. $L$ corresponds to the probe length.

\section{Concluding discussion}

From the present study it is concluded that an electrochemical wall shear rate probe can be successfully applied to flow situations where low-frequency, highamplitude fluctuations are present. Besides, its dynamical behaviour can be quite well analysed using a standard Galerkin finite-element method. The differences between theory and experiment are probably due to uncertainty in the physical parameters, the occurrence of tangential diffusion and a too coarse element distribution. More specifically, in this study a circular probe was used and its effective length for two-dimensional analyses was calculated from equation (4). Although generally speaking this relation proved to be satisfactory, especially at small $Z$-values, three-dimensional effects should not be neglected. Therefore, it is worthwhile extending the theories of Phillips (1990) and Stone (1989) to the unsteady flow case. Nevertheless, from the present study a good picture of the transducer performance is gained. Especially at high Strouhal numbers and when flow reversal occurs, the response is completely different from the quasi-steady Lévêque solution. Based upon the oscillating flow experiments of Seed \& Wood (1970) and Clark (1974) with a hot-film anemometer, Pedley (1976) mentioned $S r \geqslant 0.2$ as the value where 


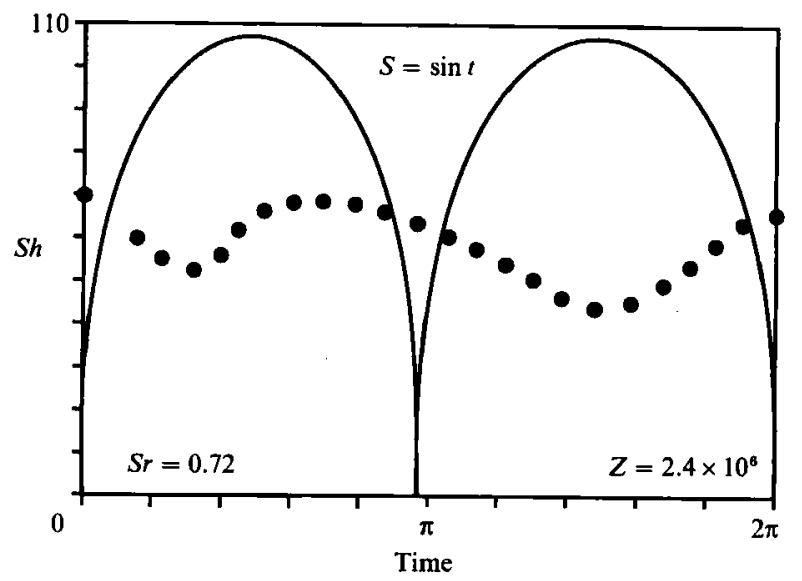

FIgure 11. Experimental response of the transducer at purely oscillating flow. As a reference also - - the Lévêque solution is given.

such a relation for calibration cannot be used, and this finding agrees quite well with our result.

The insensitivity of the transducer during flow reversal at high Strouhal values, is quite well predicted by Pedley's model and is caused by the dominant diffusion over convection process at the cathode and the reversal of fluid from the concentration wake. The response may be improved somewhat by decreases in the cathode length and in the distance between cathode and anode. Also an increase of the diffusivity (for example in case of a heat transfer probe) is favourable for the sensitivity of the transducer. However, the advantage of a higher thermal diffusivity $(\kappa=$ $\left.1.4 \times 10^{-7} \mathrm{~m}^{2} \mathrm{~s}^{-1}\right)$ than mass diffusivity $\left(D=7 \times 10^{-10} \mathrm{~m}^{2} \mathrm{~s}^{-1}\right)$ can only be used at higher shear rate values, as otherwise the avoidance of tangential diffusion will lead to a compensating larger probe design (Talbot \& Steinert 1987).

Beside the probe insensitivity during shear reversal the response is also strongly frequency dependent (Talbot \& Steinert 1987; Deslouis et al. 1990). This makes the transducer impractical for the investigation of time-dependent fluid flows with severe backflow, like those occurring in human arteries. On the other hand, in the case of a purely oscillating high-amplitude flow, like for example the situation shown in figure 11, the transducer may be useful. For those situations a further analysis of probe design and calibration relationship and interpretation of results (Mao \& Hanratty 1991) is worthwhile.

We thank P. J. B. Willems for his numerical contributions and L. H. G. Wouters and J. H. Onink (AVC) for technical assistance.

\section{REFERENCES}

Bazan, J. C. \& Arvia, A. J. 1965 The diffusion of ferro- and ferricyanide ions in aqueous solutions of sodium hydroxide. Electrochemica Acta 10, 1025-1032.

Clark, C. 1974 Thin film gauges for fluctuating velocity measurements in blood. J. Phys. E: Sci. Instrum. 7, 548-556.

Choi, U.S., TAlbot, L. \& CoRnet, I. 1979 Experimental study of wall shear rates in the entry region of a curved tube. J. Fluid Mech. 93, 465-489.

Cognet, G. 1971 Utilisation de la polarographie pour l'étude de l'écoulement de Couette. J.Méc. 10, 65-90. 
Cuvelier, C., Segal, A. \& Steenhoven, A. A. van 1986 Finite Element Methods and Navier-Stokes Equations. Reidel.

Deslouis, C., Gil, O. \& Tribollet, B. 1990 Frequency response of electrochemical sensors to hydrodynamic fluctuations. J. Fluid Mech. 215, 85-100.

Fortuna, G. \& Hanratty, T. J. 1971 Frequency response of the boundary layer on wall transfer probes. J. Heat Mass Transfer 14, 1499-1507.

Hanratty, T. J. \& Campbell, J. A. 1983 Measurement of wall shear stress. In Fluid Mechanics Measurements (ed. R. J. Goldstein), pp. 559-615. Hemisphere.

Hong, P. Z., Shu, X. B. \& Hwang, N. H. C. 1985 Wall shear stress distribution in a model human aortic arch: assessment by an electrochemical technique. J. Biomech. 18, 645-656.

KaIPING, P. 1983 Unsteady forced convective heat transfer from a hot film in non-reversing and reversing shear flow. Intl J. Heat Mass Transfer 26, 545-557.

Lévêque, M. A. 1928 Les lois de la transmission de chaleur par convection. Ann. Mines 13, 201-412.

Ling, S. C. 1963 Heat transfer from a small isothermal spanwise strip on an insulated boundary. Trans. ASME C: J. Heat Transfer 85, 230-236.

Lutz, R. J., Cannon, J. N., Bischoff, K. B., Dedrick, R. L., Stilles, R. K. \& Fry, D. L. 1977 Wall shear stress distribution in a model canine artery during steady flow. Circ. Res. 41, 391-399.

MaO, Z. X. \& Hanratty, T. J. 1985 The use of scalar transport probes to measure wall shear stress in a flow with imposed oscillations. Exps Fluids 3, 129-135.

MaO, Z. X. \& HanratTy, T. J. 1991 Analysis of wall shear stress probes in large amplitude unsteady flows. Intl $J$. Heat Mass Transfer 34, 281-290.

Mitchell, J. E. \& Hanratty, T. J. 1966 A study of turbulence at a wall using an electrochemical wall shear stress meter. J. Fluid Mech. 26, 199-221.

Mrzushina, T. 1971 The electrochemical method in transport phenomena. In Advances in Heat Transfer (ed. T. F. Irvin \& J. P. Harnet), pp. 87-161. Academic.

Pedley, T. J. 1976 Heat transfer from a hot film in reversing shear flow. J. Fluid Mech. 78, 513-534.

Phillips, C. G. 1990 Heat and mass transfer from a film into steady shear flow. Q. J. Mech. Appl. Maths 43, 135-159.

Py, B. \& Gosse, J. 1969 Sur la réalisation d'une sonde polarographique pariétale sensible à la vitesse et à la direction de l'écoulement. C. R. Acad. Sci. Paris A 269, 401-404.

Reiss, L. P. \& Hanratty, T. J. 1963 An experimental study of the unsteady nature of the viscous sublayer. AIChE J. 9, 154-160.

Schlichting, H. 1979 Boundary Layer Theory. MeGraw-Hill.

SEED, W. A. \& WoOD, N. B. 1970 Use of a hot-film velocity probe for cardiovascular studies. J. Phys. E: Sci. Instrum. 3, 377-384.

Segat, A. 1984 Sepran User Manual and Programmers Guide. Ingenierosburo Sepra, Lēidschendam.

Stone, H. A. 1989 Heat/mass transfer from surface films to shear flows at arbitrary Péclet numbers. Phys. Fluids A 1, 1112-1122.

Talbot, L. \& Wong, S. J. 1982 A note on boundary layer collision in a curved pipe. J. Fluid Mech. 122, 505-510.

Talbot, L. \& Steinert, J. J. 1987 The frequency response of electrochemical wall shear probes in pulsatile flow. J. Biomech. Engng 109, 60-64.

Uchida, S. 1956 The pulsating viscous flow superposed on the steady laminar motion of incompressible fluid in a circular pipe. Z. angew Math. Phys. 7, 403-422.

Van de Vosse, F. N., Segal, A., Steenhoven, A. A. van \& Janssen, J. D. 1986 A finite element approximation of the unsteady $2 \mathrm{D}$-Navier-Stokes equations. Intl J. Numer. Meth. Fluids 6, 427-443. 